\title{
Preface: Special Issue of the Journal of Dynamics and Differential Equations in Memory of Professor George R. Sell
}

\section{Yingfei $\mathbf{Y i}^{1}$}

Published online: 30 July 2019

○) Springer Science+Business Media, LLC, part of Springer Nature 2019

This Special Issue of the Journal of Dynamics and Differential Equations is dedicated to the memory of Professor George R. Sell, the founding editor of this journal, who passed away in May 29, 2015. We dedicate this Special Issue to Professor Sell, to acknowledge not only his important role played in the success of this journal, but also his many fundamental contributions to modern dynamics, as well as his enormous professional services to the international mathematical community.

Professor Sell was born in 1937, in Milwaukee, Wisconsin. He graduated from Marquette University in 1957 majoring in Mathematics, Physics and Philosophy, and also obtained his M.Sc. degree in Mathematics at the same university in 1958. He received his Ph.D degree in Mathematics in 1962 from the University of Michigan. After being a Benjamin Peirce Instructor for two years at Harvard University, he joined the School of Mathematics at the University of Minnesota in 1964 as an assistant professor, was promoted to an associate professor in 1968, then a full professor in 1973, and worked there until his death.

As an author of over 120 scientific articles and 5 popular books, Professor Sell is a leading figure in the modern theory of dynamical systems. Among many of his fundamental contributions to the field, in the 1960s he established the topological dynamics formulism for non-autonomous differential equations allowing the study of the lifting properties from the coefficient space and the solution space, his work in the 1970-1980s on dynamical spectrum, now widely known as the Sacker-Sell spectrum, introduced a very important characteristic and a fundamental theory into the study of linear skew-product flows, and his work from the 1990s on inertial manifolds, global attractors, fluids, and climate modeling has brought in many innovative ideas into the study of infinite dimensional dynamical systems.

Professor Sell has made many important services to the international mathematical community. In particular, he was a founder and main organizer of several very successful research centers including the Institute for Mathematics and Its Applications and the Army High Performance Computing Research Center at the University of Minnesota. He found and served as an editor-in-chief of this journal and served on the editorial board of several other professional journals.

Professor Sell's professional accomplishments and contribution to the international mathematical society have been acknowledged with high academic distinctions. He was awarded an honorary doctorate by the University of St. Petersburg (former Leningrad State University) in 1990. He was invited to deliver keynote addresses at many major mathematicalconferences,

Yingfei Yi

yingfei@ualberta.ca

1 Department of Mathematical and Statistical Sciences, University of Alberta, Edmonton, AB T6G 2G1, Canada 
including ICM, AMS/MAA annual meetings, Equadiff, and Americas DENA, and he was a tutorial /mini-course lecturers for numerous graduate summer schools worldwide. Two international conferences, the "International Conference on Dynamical Methods of Differential Equations" held in Medina del Campo, Spain in 2002 and the "International Conference on Infinite Dimensional Dynamical Systems" held in Toronto, Canada in 2008, were dedicated to the celebrations of his 65th and 70th birthday respectively. Besides this Special Issue, his many landmark contributions to the field as well as areas which he led or promoted were also documented in two special journal/book volumes in his honor: the Journal of Differential Equation (JDE) special Sell volume (J. Differential Equations Vol. 208 No. 1-2, 2005) and the Fields Institute Communication special volume "Infinite Dimensional Dynamical Systems" (Fields Inst. Comm. Vol 64, 2013). The JDE special volume also contains a biography of Professor Sell written by Victor A. Pliss. Two recent international events were dedicated to his memory, one was the Special IMA Workshop on Dynamics and Differential Equations held July 2016 in Minneapolis, USA, and the other one was the XI Americas Conference on Differential Equations and Nonlinear Analysis held in August 2017 in Edmonton, Canada. Springer has established a "Sell lecture series" with the first Sell lecture delivered by John Mallet-Paret at the XI Americas Conference.

This Special Issue was put together under the efforts of many board members, including Geneviève Raugel - a former co-editor in chief, and Russell A. Johnson and Walter Craig - two former board members, who unfortunately passed away during the preparation of the Special Issue. We thank all editors and authors of this Special Issue for their hard work and valuable contributions.

Yingfei Yi, Editor in Chief

Journal of Dynamics and Differential Equations 


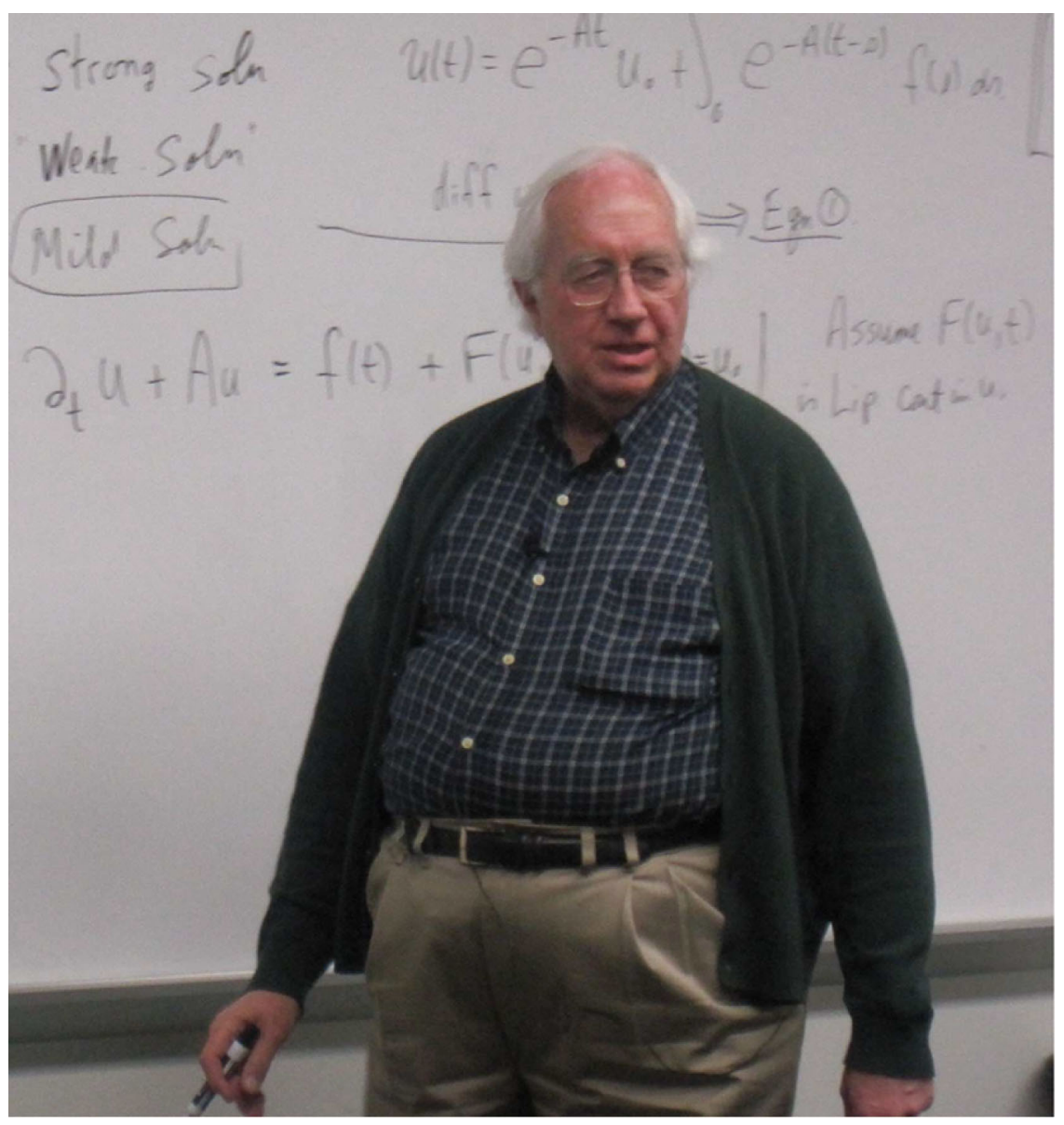

\section{Professor George R. Sell (1937-2015)}

Publisher's Note Springer Nature remains neutral with regard to jurisdictional claims in published maps and institutional affiliations. 